\title{
Synthesis of new naphthoquinones with antifungal activity.
}

\author{
Larissa Lopes Roldi (IC), Sandro José Greco (PQ), Valdemar Lacerda Júnior (PQ), \\ Reginaldo Bezerra dos Santos (PQ), Eustáquio V. R. de Castro (PQ)
}

Organic Chemistry Research Laboratory, Department of Chemistry-CCE/UFES, Vitória-ES, Brazil

*Corresponding author: sandrogreco.ufes@gmail.com

Keywords: Lawsone, Triazolic Aldehyde, Morpholine and Antifungal.

\section{INTRODUCTION}

The massive emergence of fungal diseases associated with AIDS in the 1980s and the rising frequency of fatal mycoses associated with increasing use of immunosuppressive medical therapies since the 1970s stimulated research directed towards the discovery of novel antifungal agents. Azoles, allylamines and morpholine are the largest class of antifungal agents in clinical use. Their main effect is to inhibit ergosterol biosynthetic pathway. When ergosterol is depleted, the normalpermeability and fluidity of the fungal membrane is altered, with secondary consequences for membrane-bound enzymes, such as those involved in cell wall synthesis. In addition to the agents mentioned above, the 1,4-naphtoquinones, natural and synthetic, are a very interesting compound class because of the diverse biological activities present, among which, fungicide and fungistatic actions. ${ }^{2}$ In order to study the synergy of activities, the objective of this work consists in the synthesis of substances derived from lawsone containing the 1,2,3-triazole and morpholine rings.

\section{RESULTS AND DISCUSSION}

The phenyl triazolic aldehyde 1 was obtained from the D-glucose in a synthetic sequence of three stages, as described in the literature (Scheme 1). ${ }^{3}$

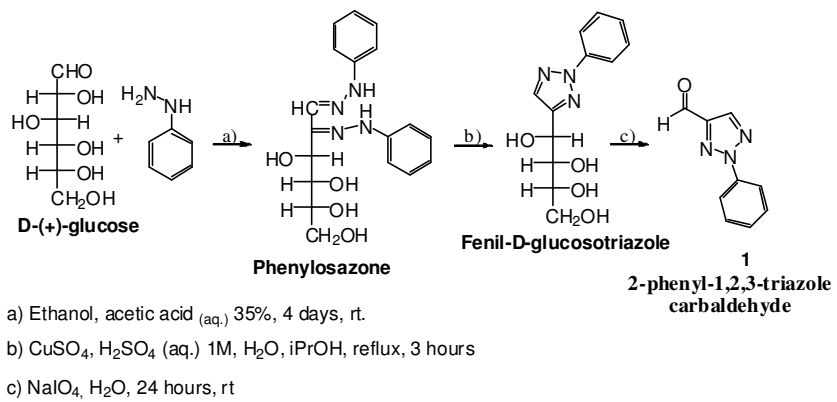

Scheme 1: Phenyl triazolic aldehyde synthesis.

The coupling of 1,2,3-triazole rings and morpholine to the naphthoquinone structure was performed in one step via a Mannich reaction (Scheme 2). ${ }^{4}$ The Mannich adduct 2 was obtained in $50 \%$ yield and characterized by IR, ${ }^{1} \mathrm{H}$ and ${ }^{13} \mathrm{C}$ spectroscopy.

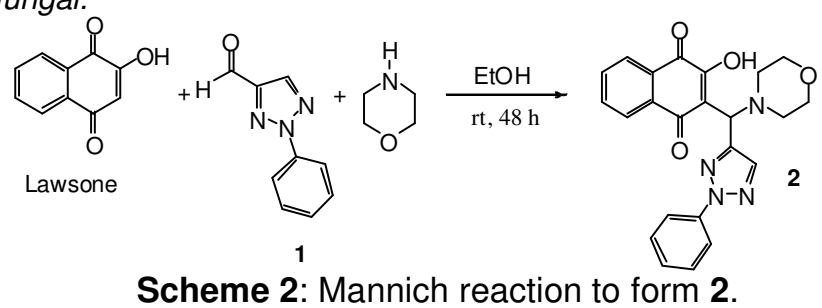

The Mannich base 2 was then subjected to benzylation reaction in $\mathrm{EtOH}$ and nucleophilic displacement with picolylamine in $\mathrm{CH}_{3} \mathrm{OH}$ (Scheme 3). The products 3 and 4 were obtained in 40 and 60 $\%$ yield, respectively and characterized by $I R,{ }^{1} \mathrm{H}$ and ${ }^{13} \mathrm{C}$ NMR.

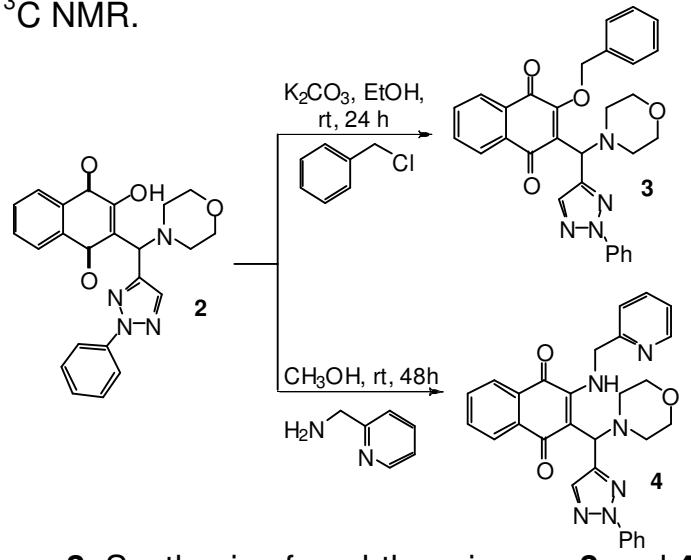

Scheme 3: Synthesis of naphthoquinones $\mathbf{3}$ and 4.

\section{CONCLUSION}

In this work we report the synthesis of new naphthoquinones derives from lawsone, both in moderate yields. The products 3 and 4 presented antifungal activity against Candida krusei and Candida albicans using the methods of diffusion in agar. The microdilution assay, with subsequent calculation of MIC, are underway.

\section{ACKNOWLEDGEMENTS}

PIBIC/UFES, FAPES, LabPetro/DQUI/UFES

\section{REFERENCES}

${ }^{1}$ Odds, F.C.; Brown, A.J.P.; Gow, N.A.R. TRENDS in Microbiology 2003, 11(6), 272; ${ }^{2}$ de Souza, M.A.A; da Silva, A.R; Ferreira, M.A., de Lemos, M.J.; Ramos, M.G.; Ferreira, A.B.B.; de Souza, S.R. Quim. Nova 2008, 31(7), 1670; ${ }^{3}$ Hann, R.M.; Hudson, C.S. J. Org. Chem. 1944, 66, 735; ${ }^{4}$ Vargas, M.D.; Greco, S.J.; Neves, A.P.; Barbosa, C.C.; Visentin, L.C.; Pinheiro, C.B.; Mangrich, A.S.; Barbosa, J.P; da Costa, G.L J. Braz. Chem. Soc. 2009, 20(4), 712-727; 